\title{
Rituximab plus cyclophosphamide, doxorubicin, vincristine, and prednisolone in patients with newly diagnosed diffuse large B-cell non-Hodgkin lymphoma: a phase 3 comparison of dose intensification with 14-day versus 21-day cycles
}

\author{
David Cunningham*, Eliza A Hawkes*, Andrew Jack, Wendi Qian, Paul Smith, Paul Mouncey, Christopher Pocock, Kirit M Ardeshna, \\ John A Radford, Andrew McMillan, John Davies, Deborah Turner, Anton Kruger, Peter Johnson, Joanna Gambell, David Linch
}

\begin{abstract}
Summary
Background Dose intensification with a combination of cyclophosphamide, doxorubicin, vincristine, and prednisolone (CHOP) every 2 weeks improves outcomes in patients older than 60 years with diffuse large B-cell lymphoma compared with CHOP every 3 weeks. We investigated whether this survival benefit from dose intensification persists in the presence of rituximab (R-CHOP) in all age groups.
\end{abstract}

Methods Patients (aged $\geq 18$ years) with previously untreated bulky stage IA to stage IV diffuse large B-cell lymphoma in 119 centres in the UK were randomly assigned centrally in a one-to-one ratio, using minimisation, to receive six cycles of R-CHOP every 14 days plus two cycles of rituximab (R-CHOP-14) or eight cycles of R-CHOP every 21 days (R-CHOP-21). R-CHOP-21 was intravenous cyclophosphamide $750 \mathrm{mg} / \mathrm{m}^{2}$, doxorubicin $50 \mathrm{mg} / \mathrm{m}^{2}$, vincristine $1.4 \mathrm{mg} / \mathrm{m}^{2}$ (maximum dose $2 \mathrm{mg}$ ), and rituximab $375 \mathrm{mg} / \mathrm{m}^{2}$ on day 1 , and oral prednisolone $40 \mathrm{mg} / \mathrm{m}^{2}$ on days $1-5$, administered every 21 days for a total of eight cycles. R-CHOP-14 was intravenous cyclophosphamide $750 \mathrm{mg} / \mathrm{m}^{2}$, doxorubicin $50 \mathrm{mg} / \mathrm{m}^{2}$, vincristine $2 \mathrm{mg}$, rituximab $375 \mathrm{mg} / \mathrm{m}^{2}$ on day 1 , and oral prednisolone $100 \mathrm{mg}$ on days $1-5$, administered every 14 days for six cycles, followed by two further infusions of rituximab $375 \mathrm{mg} / \mathrm{m}^{2}$ on day 1 every 14 days. The trial was not masked. The primary outcome was overall survival (OS). This study is registered, number ISCRTN 16017947.

Findings 1080 patients were assigned to R-CHOP-21 $(\mathrm{n}=540)$ and R-CHOP-14 $(\mathrm{n}=540)$. With a median follow-up of 46 months (IQR 35-57), 2-year OS was $82 \cdot 7 \%(79 \cdot 5-85 \cdot 9)$ in the R-CHOP-14 group and $80 \cdot 8 \%(77 \cdot 5-84 \cdot 2)$ in the R-CHOP-21 (standard) group (hazard ratio $0 \cdot 90,95 \%$ CI $0 \cdot 70-1 \cdot 15 ; \mathrm{p}=0 \cdot 3763$ ). No significant improvement was noted

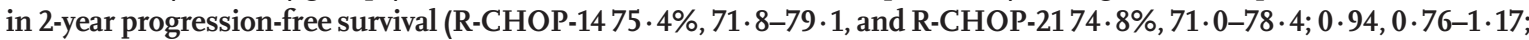
$\mathrm{p}=0$. 5907). High international prognostic index, poor-prognosis molecular characteristics, and cell of origin were not predictive for benefit from either schedule. Grade 3 or 4 neutropenia was higher in the R-CHOP-21 group (318 [60\%] of 534 vs 167 [31\%] of 534), with no prophylactic use of recombinant human granulocyte-colony stimulating factor mandated in this group, whereas grade 3 or 4 thrombocytopenia was higher with R-CHOP-14 (50 [9\%] vs 28 [5\%]); other frequent grade 3 or 4 adverse events were febrile neutropenia (58 [11\%] vs 28 [5\%]) and infection (125 [23\%] vs 96 [18\%]). Frequencies of non-haematological adverse events were similar in the R-CHOP-21 and R-CHOP-14 groups.

Interpretation R-CHOP-14 is not superior to R-CHOP-21 chemotherapy for previously untreated diffuse large B-cell lymphoma; therefore, R-CHOP-21 remains the standard first-line treatment in patients with this haematological malignancy. No molecular or clinical subgroup benefited from dose intensification in this study.

Funding Chugai Pharmaceutical, Cancer Research UK, National Institute for Health Research Biomedical Research Centres scheme at both University College London and the Royal Marsden NHS Foundation Trust, and Institute of Cancer Research.

\section{Introduction}

Diffuse large B-cell lymphoma represents more than $30 \%$ of all diagnoses of non-Hodgkin lymphoma. Combination chemotherapy with cyclophosphamide, doxorubicin, vincristine, and prednisolone (CHOP) was established as a standard treatment almost 40 years ago. Intensive regimens have not consistently improved outcomes compared with CHOP every 3 weeks (CHOP-21), including the use of high-dose treatment plus autologous stem-cell transplant. ${ }^{2,3}$ However, in 2004, the results of the German High-Grade Lymphoma
Study Group phase 3 study showed superior overall survival (OS) with six cycles of CHOP every 14 days (CHOP-14) compared with six cycles of CHOP-21 in patients aged 60 years and older, ${ }^{4}$ although these results were not replicated in a smaller Japanese study of eight cycles of CHOP-14 versus CHOP-21 in patients with aggressive non-Hodgkin lymphoma, only $58 \%$ of whom had diffuse large B-cell lymphoma. ${ }^{5}$ Incorporation of etoposide into CHOP improved response rates and event-free survival in young patients, but did not affect overall survival in any age group. ${ }^{4,6}$ An alternative

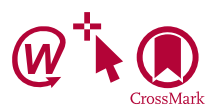

CrossMark

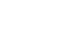


dose-intense regimen of cyclophosphamide, vindesine, bleomycin, and prednisolone followed by high-dose methotrexate, ifosfamide, and cytarabine (ACVBP) also improved survival compared with standard CHOP-21 in both localised disease and poor-prognosis aggressive non-Hodgkin lymphoma but the results did not change clinical practice, probably due to toxicity of the polydrug combination., ${ }^{7,8}$

Concurrent with these results, rituximab, an antiCD20 monoclonal antibody, combined with CHOP-21 improved cure rates by $10-15 \%$ compared with CHOP-21 alone without serious additional toxicity in the pivotal phase 3 Groupe d'Etude des Lymphomes de l'Adulte (GELA) trial;, ${ }^{910}$ the results were confirmed in a subsequent US intergroup study. ${ }^{11}$ Rituximab also added benefit to CHOP-14 (R-CHOP-14) in patients older than 60 years in the RICOVER-60 trial, ${ }^{12}$ and in young patients (aged 18-60 years) with a good prognosis in the MiNT study. ${ }^{13}$

However, whether the improved survival reported with CHOP-14 by the German group ${ }^{4}$ was still evident in

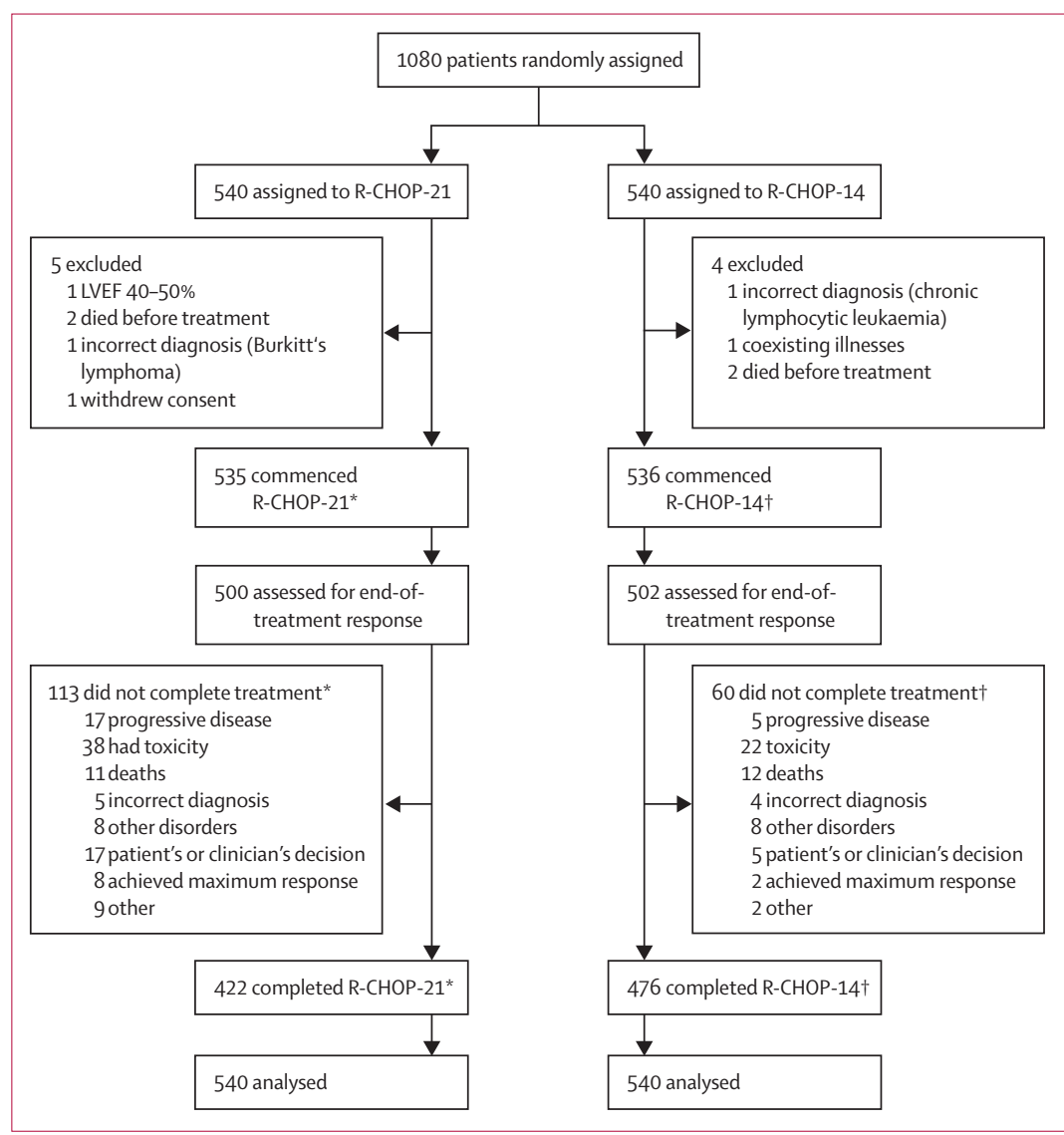

Figure 1: Trial profile

R-CHOP-21=cycles of rituximab plus cyclophosphamide, doxorubicin, vincristine, and prednisolone every 21 days. R-CHOP-14=cycles of rituximab plus cyclophosphamide, doxorubicin, vincristine, and prednisolone every 14 days. LVEF=left ventricular ejection fraction. *Includes 35 people who did not have an end-of-treatment scan and therefore were not assessable for end-of-treatment response. tIncludes 34 people who did not have an end-of-treatment scan and therefore were not assessable for end-of-treatment response. patients receiving rituximab remained uncertain. Therefore, in 2005, the UK National Cancer Research Institute Lymphoma Clinical Study Group commenced a large, randomised study of all patients older than 18 years with previously untreated diffuse large B-cell lymphoma to compare CHOP-14 with CHOP-21 in patients receiving rituximab. This phase 3 , open-label randomised study was designed to detect superior OS of the dose-intense regimen R-CHOP-14 versus standard R-CHOP-21 in patients of all age groups and all risk strata.

\section{Methods \\ Patients}

In this phase 3 study, patients with diffuse large B-cell lymphoma were enrolled in 119 centres in the UK. Eligible patients were aged 18 years and older with previously untreated, histologically confirmed, diffuse large B-cell lymphoma according to the WHO classification. ${ }^{14}$ Patients were required to have Ann Arbor bulky stage IA (tumour mass diameter $>10 \mathrm{~cm}$ ) or stage IB-IV disease, a good performance status (WHO grade 0-2), adequate cardiac, renal, hepatic, and haematological function (initial neutrophil count $>1 \cdot 5 \times 10^{9}$ per L, initial platelet count $>100 \times 10^{9}$ per L unless the abnormality was caused by lymphoma rather than another disease in which case the patient was eligible). Patients with T-cell lymphomas, transformed follicular lymphoma, or a history of indolent lymphoma were excluded. However, patients with previously undiagnosed concurrent smallcell infiltration in bone marrow or lymph node were eligible. Patients with CNS involvement, positive serology for HIV, hepatitis B or hepatitis C virus, a history of heart failure or uncontrolled angina pectoris, active malignancy in the preceding 10 years, or other illnesses precluding administration of study treatment were ineligible.

The trial was overseen by a trial steering committee and an independent data monitoring committee. The protocol was approved by the UK Medicines and Healthcare products Regulatory Agency and Hull and East Riding Research Ethics Committee, and done in accordance with the Declaration of Helsinki and the European Union Clinical Trials Directive 2001/20/EC. Patients provided written informed consent.

\section{Randomisation and masking}

Randomisation was done centrally by the Cancer Research UK and University College London Cancer Trials Centre, London, UK, using a minimisation procedure, stratified for international prognostic index (IPI) and centre. Patients were allocated in a one-to-one ratio to $\mathrm{R}-\mathrm{CHOP}-21$ or $\mathrm{R}-\mathrm{CHOP}-14$ regimens. The trial was not masked.

\section{Procedures}

The R-CHOP-21 regimen was based on the original doses used by the GELA group ${ }^{9}$ and consisted of intravenous cyclophosphamide $750 \mathrm{mg} / \mathrm{m}^{2}$, doxorubicin $50 \mathrm{mg} / \mathrm{m}^{2}$, 
vincristine $1.4 \mathrm{mg} / \mathrm{m}^{2}$ (maximum dose $2 \mathrm{mg}$ ), rituximab $375 \mathrm{mg} / \mathrm{m}^{2}$ on day 1 , and oral prednisolone $40 \mathrm{mg} / \mathrm{m}^{2}$ on days 1-5, administered every 21 days for a total of eight cycles. R-CHOP-14, designed by the German High Grade Lymphoma Study Group, ${ }^{4}$ consisted of intravenous cyclophosphamide $750 \mathrm{mg} / \mathrm{m}^{2}$, doxorubicin $50 \mathrm{mg} / \mathrm{m}^{2}$, vincristine $2 \mathrm{mg}$, rituximab $375 \mathrm{mg} / \mathrm{m}^{2}$ on day 1 , and oral prednisolone $100 \mathrm{mg}$ on days $1-5$, administered every 14 days for six cycles followed by two further infusions of rituximab $375 \mathrm{mg} / \mathrm{m}^{2}$ on day 1 every 14 days. The recombinant human granulocyte-colony stimulating factor (G-CSF) lenograstim was administered on days 4-12 of each cycle to patients randomly assigned to R-CHOP-14 whereas use of G-CSF for patients receiving R-CHOP-21 was at the discretion of the investigators. All patients received allopurinol $300 \mathrm{mg} /$ day for the first cycle and co-trimoxazole $480 \mathrm{mg}$ twice daily for 3 days per week until 2 weeks after the end of treatment. Other supportive medications were given according to local protocols. Prophylaxis for CNS relapse was at the discretion of the investigators; however, the recommendation was that patients with large-cell lymphoma involvement of the bone marrow, peripheral blood, nasal or paranasal sinuses, orbit, and testis receive $12.5 \mathrm{mg}$ intrathecal methotrexate for the first three cycles of treatment, administered as per local guidelines. Consolidation radiotherapy was also permitted at the discretion of the investigators.

Patients were assessed before treatment; at each attendance for treatment; and then after treatment every 3 months until 1 year, then every 6 months until 2 years, and thereafter every year. Reports by clinicians included details of treatment and adverse effects, performance status, and results of blood counts and other relevant tests. CT scans of the chest, abdomen, pelvis, with or without neck were done at baseline, after four cycles of chemotherapy, at the end of treatment, and at 3 months and 12 months after completion of treatment. In the event of clinical suspicion of relapse, additional imaging was done. ${ }^{18 F}$-fluorodeoxyglucose (18F-FDG) PET scans were not mandated and therefore no PET data were gathered as part of the main study.

Central pathology review was done by an expert haematopathologist (AJ). A full immunohistochemical panel was done for all available specimens and included CD20, CD79a, P53 expression, and the proliferation index (MIB1). Molecular phenotype (germinal centre vs non-germinal centre) was determined using the Hans criteria. ${ }^{15}$ Fluorescence in-situ hybridisation (FISH) was done according to reported methods ${ }^{16}$ to detect $M Y C$, $B C L 6$, and BCL2 rearrangements.

\section{Statistical analysis}

The primary outcome was OS. The secondary outcomes were progression-free survival (PFS), toxicity, and response rate. The method of analysis was intention to treat.

The sample size was based on an estimated 2-year OS of $70 \%$ in the R-CHOP-21 group; the aim in the trial

\begin{tabular}{|c|c|c|}
\hline & R-CHOP-21 $(n=540)$ & $\mathrm{R}-\mathrm{CHOP}-14(\mathrm{n}=540)$ \\
\hline \multicolumn{3}{|l|}{ Age (years; median, range) } \\
\hline Median (years) & $61(19-88)$ & $61(19-85)$ \\
\hline$\leq 60$ & $239(44 \%)$ & $237(44 \%)$ \\
\hline$>60$ & $301(56 \%)$ & $303(56 \%)$ \\
\hline \multicolumn{3}{|l|}{ Sex } \\
\hline Male & $293(54 \%)$ & $289(54 \%)$ \\
\hline Female & $247(46 \%)$ & $251(46 \%)$ \\
\hline \multicolumn{3}{|l|}{ WHO performance status } \\
\hline 0 & $258(48 \%)$ & $286(53 \%)$ \\
\hline 1 & $210(39 \%)$ & $182(34 \%)$ \\
\hline 2 & $72(13 \%)$ & $72(13 \%)$ \\
\hline \multicolumn{3}{|l|}{ Stage } \\
\hline Bulky IA & $20(4 \%)$ & $26(5 \%)$ \\
\hline IB & $16(3 \%)$ & $17(3 \%)$ \\
\hline$\|$ & $166(31 \%)$ & $157(29 \%)$ \\
\hline III & $142(26 \%)$ & $175(32 \%)$ \\
\hline IV & $193(36 \%)$ & $162(30 \%)$ \\
\hline Bulky disease & $272(50 \%)$ & $261(48 \%)$ \\
\hline B symptoms & $238(44 \%)$ & $251(46 \%)$ \\
\hline Elevated lactate dehydrogenase & $350(65 \%)$ & $351(65 \%)$ \\
\hline \multicolumn{3}{|l|}{ International prognostic index score } \\
\hline 0 & $43(8 \%)$ & $40(7 \%)$ \\
\hline 1 & $117(22 \%)$ & $116(21 \%)$ \\
\hline 2 & $143(26 \%)$ & $163(30 \%)$ \\
\hline 3 & $143(26 \%)$ & $136(25 \%)$ \\
\hline 4 & $79(15 \%)$ & $75(14 \%)$ \\
\hline 5 & $15(3 \%)$ & $10(2 \%)$ \\
\hline Phenotype & 275 & 285 \\
\hline Germinal centre & $145(53 \%)$ & $144(51 \%)$ \\
\hline Non-germinal centre & $130(47 \%)$ & $141(49 \%)$ \\
\hline Proliferation rate & 262 & 265 \\
\hline MIB1 $\geq 80 \%$ & $127(48 \%)$ & $106(40 \%)$ \\
\hline MIB1 $\geq 90 \%$ & $71(27 \%)$ & $49(18 \%)$ \\
\hline P53 overexpression & 136/299 (45\%) & $171 / 309(55 \%)$ \\
\hline MYC rearrangement & $16 / 175(9 \%)$ & 20/184 (11\%) \\
\hline BCL2 translocation & $41 / 178(23 \%)$ & 49/190 (26\%) \\
\hline$B C L 6$ rearrangement & $32 / 176(18 \%)$ & $44 / 185(24 \%)$ \\
\hline MYC plus BCL2 (double-hit abnormality) & $5 / 172(3 \%)$ & $11 / 182(6 \%)$ \\
\hline Other disease types diagnosed at central review & 12 & 12 \\
\hline Burkitt's lymphoma & 0 & $1(<1 \%)$ \\
\hline B-cell chronic lymphocytic leukaemia & $1(<1 \%)$ & $3(<1 \%)$ \\
\hline Follicular lymphoma & $4(<1 \%)$ & $4(<1 \%)$ \\
\hline Marginal zone lymphoma & $2(<1 \%)$ & 0 \\
\hline B-cell non-Hodgkin lymphoma not otherwise classified & 0 & $2(<1 \%)$ \\
\hline Indolent lymphoma not otherwise classified & $1(<1 \%)$ & 0 \\
\hline Hodgkin's lymphoma & $2(<1 \%)$ & 0 \\
\hline Lymphocyte predominant Hodgkin's lymphoma & $1(<1 \%)$ & 0 \\
\hline Peripheral T-cell lymphoma & $1(<1 \%)$ & $1(<1 \%)$ \\
\hline No lymphoma & 0 & $1(<1 \%)$ \\
\hline \multicolumn{3}{|c|}{$\begin{array}{l}\text { Data are number, number (\%), or } \mathrm{n} / \mathrm{N}(\%) \text {. R-CHOP-21=cycles of rituximab plus cyclophosphamide, doxorubicin, } \\
\text { vincristine, and prednisolone every } 21 \text { days. R-CHOP-14=cycles of rituximab plus cyclophosphamide, doxorubicin, } \\
\text { vincristine, and prednisolone every } 14 \text { days. }\end{array}$} \\
\hline
\end{tabular}




\begin{tabular}{|c|c|c|c|c|}
\hline & \multicolumn{2}{|c|}{$\begin{array}{l}\text { Median total dose received/ } \\
\text { planned total dose }(\mathrm{mg})\end{array}$} & \multicolumn{2}{|c|}{$\begin{array}{l}\text { Median dose intensity achieved/ } \\
\text { planned dose intensity } \\
\left(\mathrm{mg} / \mathrm{m}^{2} \text { per day) }\right.\end{array}$} \\
\hline & R-CHOP-21 & R-CHOP-14 & R-CHOP-21 & R-CHOP-14 \\
\hline Cyclosphosphamide & $98 \%(88-100)$ & $100 \%(97-100)$ & $96 \%(91-100)$ & $98 \%(92-100)$ \\
\hline Doxorubicin & $99 \%(87-100)$ & $100 \%(97-100)$ & $96 \%(91-100)$ & $98 \%(92-100)$ \\
\hline Vincristine & $100 \%(75-100)$ & $100 \%(83-100)$ & $71 \%(65-75)$ & $98 \% *(84-100)$ \\
\hline Prednisolone & $99 \%(90-102)$ & $100 \%(100-100)$ & $98 \%(92-100)$ & $99 \%{ }^{*}(92-100)$ \\
\hline Rituximab & $98 \%(87-100)$ & $99 \%(94-100)$ & $96 \%(91-100)$ & $97 \%(90-100)$ \\
\hline \multicolumn{5}{|c|}{$\begin{array}{l}\text { Data are \% (IQR). R-CHOP-21=cycles of rituximab plus cyclophosphamide, doxorubicin, vincristine, and prednisolone } \\
\text { every } 21 \text { days. R-CHOP-14=cycles of rituximab plus cyclophosphamide, doxorubicin, vincristine, and prednisolone } \\
\text { every } 14 \text { days. *Vincristine and prednisolone were fixed doses and not calculated according to body surface area in the } \\
\text { R-CHOP-14 group; therefore, median dose intensities were calculated in } \mathrm{mg} / \text { day. }\end{array}$} \\
\hline
\end{tabular}

\begin{tabular}{|c|c|c|c|c|}
\hline & $\begin{array}{l}\text { R-CHOP-21 } \\
(n=500)\end{array}$ & $\begin{array}{l}\text { R-CHOP-14 } \\
(n=502)\end{array}$ & $\begin{array}{l}\text { Difference } \\
(95 \% \mathrm{Cl})^{*}\end{array}$ & $\mathrm{p}$ value \\
\hline Complete response & $243(49 \%)$ & $207(41 \%)$ & .. & .. \\
\hline Unconfirmed complete response & $70(14 \%)$ & $87(17 \%)$ & & .. \\
\hline Partial response & $126(25 \%)$ & $162(32 \%)$ & .. & .. \\
\hline Stable disease & $31(6 \%)$ & $25(5 \%)$ & .. & .. \\
\hline Progressive disease or relapse & $30(6 \%)$ & $21(4 \%)$ & .. & .. \\
\hline $\begin{array}{l}\text { Complete response or unconfirmed } \\
\text { complete response }\end{array}$ & $313(63 \%)$ & $292(58 \%)$ & $5 \%(-2$ to 10$)$ & 0.1830 \\
\hline Overall response rate & $439(88 \%)$ & $456(91 \%)$ & $-3 \%(-7$ to 1$)$ & 0.1223 \\
\hline
\end{tabular}

Data are number (\%), unless otherwise indicated. R-CHOP-21=cycles of rituximab plus cyclophosphamide, doxorubicin vincristine, and prednisolone every 21 days. R-CHOP-14=cycles of rituximab plus cyclophosphamide, doxorubicin vincristine, and prednisolone every 14 days. *Only reported for secondary endpoints.

Table 3: Response to treatment progression or relapse were censored at the date they were last known to be alive.

Response was assessed by the local treating physician as complete response (CR), unconfirmed complete response $(\mathrm{CRu})$, partial response $(\mathrm{PR})$, stable disease, or progressive disease (PD) in accordance with the International Workshop Standardized Response Criteria for Non-Hodgkin Lymphoma. ${ }^{17}$ The severity of adverse events was defined according to the National Cancer Institute Common Terminology Criteria for Adverse Events (NCI-CTCAE, version 3.0).

The log-rank test was used to compare the KaplanMeier curves for OS and PFS. The $\chi^{2}$ test for interaction or trend was used to ascertain the differences in the benefits of R-CHOP-14 in different patients subgrouped according to baseline characteristics. The response achieved during treatment was compared by use of the Mann-Whitney test. Patients who received at least one cycle of assigned protocol treatment were included in the safety analyses. Cox regression model was applied in the prognostic analyses. All p values were two-sided.

This study is registered, number ISCRTN 16017947.

\section{Role of the funding source}

The trial sponsor (University College London) was responsible for randomisation, data gathering, entry, and validation, monitoring procedures, reporting of serious adverse events, organisation of central pathological review, liaison with investigators, statistical analysis, and production of the report. Chugai Pharmaceutical had no role in study design, data gathering or interpretation, statistical analysis, or the writing of the report. The corresponding author had full access to all the data in the study and had final responsibility for the decision to submit for publication.

improvement of $8 \%$ (from $70 \%$ with R-CHOP-14. With 5\% significance and $90 \%$ power (two-sided), a total of 330 OS events were needed. The plan was to randomly assign a total of 1080 patients over 3 years. The required number of OS events was expected to occur 1 year after the last patient was randomly assigned.

The total number of OS events reported $(n=182) 1$ year after the completion of recruitment was much lower than expected; therefore, the statistical plan was amended on the basis of the estimates from the combined groups without formal comparisons between groups: the estimated 2-year OS in the R-CHOP-21 group was about $75-80 \%$, and a total of 233 OS events would be needed to detect a 7-8\% difference in OS with $5 \%$ significance level and $90 \%$ power. The amendment was approved by the steering committee and independent data monitoring committee.

OS was calculated from the date of randomisation until the date of death from any cause; patients still alive were censored at the date they were last known to be alive.

PFS was calculated from the date of randomisation to the date of first appearance of disease progression, relapse, or death from any cause; patients alive without

\section{Results}

From March, 2005, to November, 2008, 1080 patients were randomly assigned to treatment (540 in each group). Nine patients did not commence treatment due to consent withdrawal, illness, or death (figure 1). Baseline characteristics of patients, including IPI, were well balanced between groups (table 1). 937 patients (459 in R-CHOP-21 group and 478 in R-CHOP-14 group) had central pathology review; up to 560 patients (275 and 285 , respectively) were assessable for molecular characteristics and the groups were also well balanced (table 1).

422 (78\%) of 540 patients completed all eight cycles of R-CHOP-21 and 476 (88\%) of 540 completed per-protocol R-CHOP-14; 91\% in each group (489 in R-CHOP-21 group and 494 in R-CHOP-14 group) completed at least six cycles. Table 2 shows that the percentages for the median total dose received for each drug by treatment group were similar in the R-CHOP-21 and R-CHOP-14 groups; the median dose intensities achieved for each drug by treatment group were also similar with the exception of vincristine. In the R-CHOP-21 group, 420 (78\%), 
417 (77\%), 439 (81\%), 371 (69\%), and 432 (80\%) patients received at least $80 \%$ of the planned total dose of cyclosphosphamide, doxorubicin, prednisolone, vincristine, and rituximab, respectively. In the R-CHOP-14 group, 497 (92\%), 494 (91\%), 500 (93\%), 444 (82\%), and 469 (87\%) patients received at least $80 \%$ of the planned total dose of cyclosphosphamide, doxorubicin, prednisolone, vincristine, and rituximab, respectively. The median dose intensity for individual drugs in the R-CHOP-14 group relative to the R-CHOP-21 group was $152 \%$ for cyclophosphamide, $152 \%$ for doxorubicin, $148 \%$ for vincristine, 191\% for prednisolone, and $151 \%$ for rituximab.

All 540 patients in the R-CHOP-14 group received G-CSF as per-protocol treatment; 293 (54\%) of 540 patients in the R-CHOP-21 group were given G-CSF as secondary prophylaxis. $54(10 \%)$ patients in the R-CHOP-21 group and $51(9 \%)$ in the R-CHOP-14 group underwent radiotherapy after chemotherapy.

Response after four cycles was assessable in 981 (91\%) of 1080 patients, with CR or CRu documented in 169 (34\%) of 490 patients in the R-CHOP-21 group and 159 (32\%) of 491 in the R-CHOP-14 group. End-of-treatment response was assessable in 1002 (93\%) patients who received at least one cycle of treatment. $\mathrm{CR}$ or $\mathrm{CRu}$ at the end of treatment, as assessed by use of CT scanning, was noted in $63 \%$ of patients in the R-CHOP-21 group and $58 \%$ of those receiving $\mathrm{R}-\mathrm{CHOP}-14(\mathrm{p}=0 \cdot 1830$; table 3$)$. The difference in overall response rate between treatment groups was not significant (88\% patients in R-CHOP-21 group vs 91\% in R-CHOP-14 group; $\mathrm{p}=0 \cdot 1223$; table 3 ).

At the time of the analysis, median follow-up was 46 months (IQR 35-57). The 2-year PFS was 74.8\% (95\% CI 71.0-78.4) in the R-CHOP-21 group and $75.4 \%$ $(71 \cdot 8-79 \cdot 1)$ in the R-CHOP-14 group (figure 2A). 14 (1\%) CNS relapses (eight in R-CHOP-21 group and six in R-CHOP-14 group) were reported, with isolated recurrences in seven of these patients (four $[<1 \%]$ in the R-CHOP-21 group and three $[<1 \%]$ in the R-CHOP-14 group). The 2-year OS was $80.8 \%(77 \cdot 5-84 \cdot 2)$ in the R-CHOP-21 group and $82.7 \%(79.5-85.9)$ in the R-CHOP-14 group (figure 2B).

By use of the Cox regression model for prognostic factor analysis with both groups combined, a higher IPI was associated with worse OS: IPI 4 or 5 versus $0-3$ (hazard ratio [HR] 2.15, 95\% CI 1.63-2.83; p<0.0001). Multivariate Cox regression analysis of individual prognostic factors, including age as a continuous variable, showed that age $(p<0 \cdot 0001)$, stage $(p=0 \cdot 0007)$, WHO performance status $(\mathrm{p}<0 \cdot 0001)$, raised lactate dehydrogenase concentration $(\mathrm{p}=0.0007)$, and presence of B symptoms $(\mathrm{p}=0.0486)$ were independent prognostic factors $(\mathrm{p}<0.05$ deemed significant).

According to the results of the molecular analysis, MYC rearrangement $(n=36)$ was prognostic for OS (2-year OS, MYC-rearranged $75 \%$, 95\% CI $60 \cdot 7-89 \cdot 0$, vs MYCnormal 85\%, 80.7-88.6; HR 2.08, 1·15-3.78; $\mathrm{p}=0 \cdot 0160$ ) and when adjusted for age, sex, stage, presence of

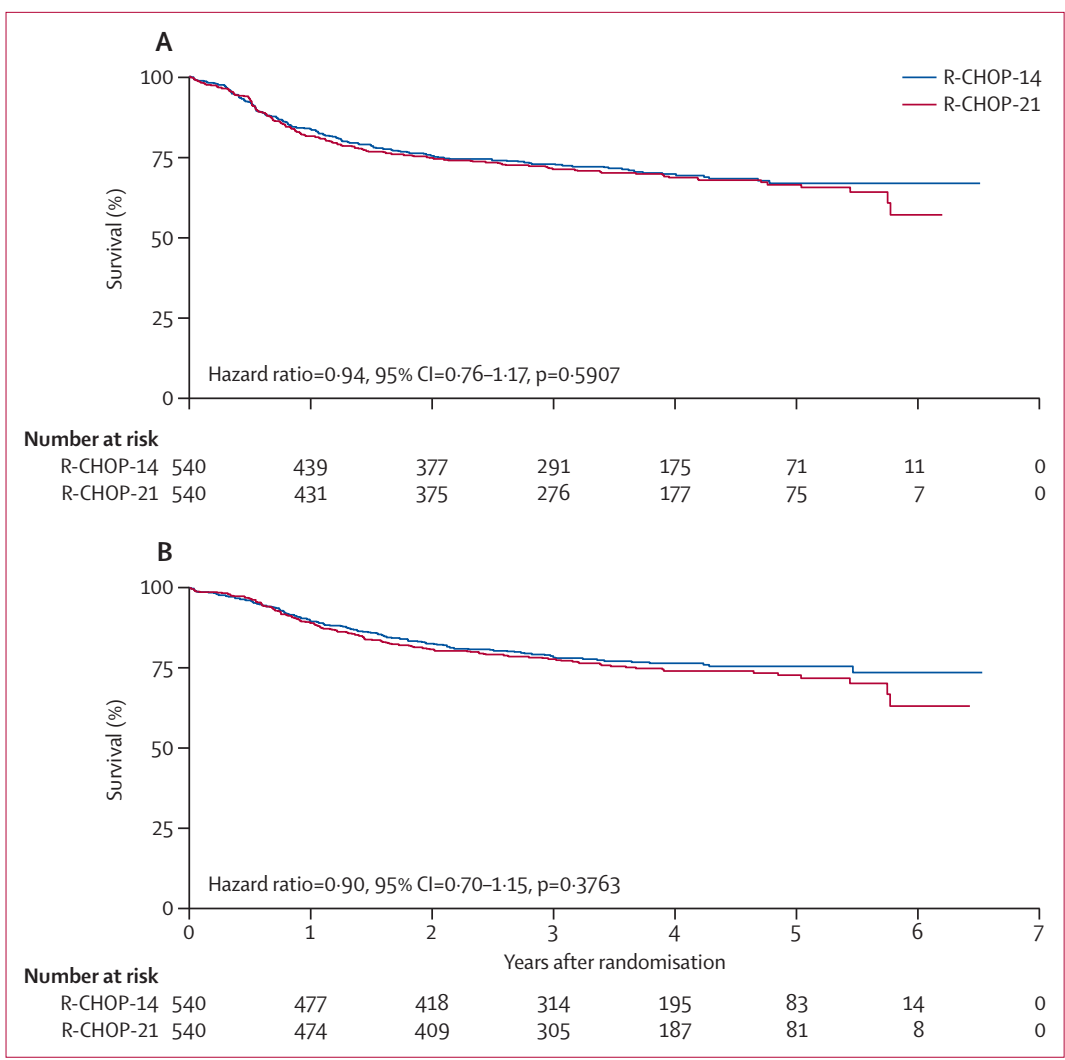

Figure 2: Progression-free survival (A) and overall survival (B) according to treatment

R-CHOP-14=cycles of rituximab plus cyclophosphamide, doxorubicin, vincristine, and prednisolone every 14 days. R-CHOP-21=cycles of rituximab plus cyclophosphamide, doxorubicin, vincristine, and prednisolone every 21 days.

B symptoms, bulky disease, WHO performance status, and raised lactate dehydrogenase concentrations, survival was non-significantly worse $(1 \cdot 71,0 \cdot 92-3 \cdot 18 ; \mathrm{p}=0 \cdot 0875)$. The so-called double-hit mutation (both MYC and BCL2 rearrangements; $n=16$ ) was non-significantly prognostic for 2-year OS (double-hit 63\%, 38-8-86.1, vs no doublehit $84 \%, 80 \cdot 5-88 \cdot 3 ; 2 \cdot 24,95 \%$ CI $0 \cdot 98-5 \cdot 17 ; p=0 \cdot 0575)$, which was maintained in the multivariate analysis $(2 \cdot 03,0 \cdot 87-4 \cdot 73 ; p=0 \cdot 1023)$. No other assessments with immunohistochemistry or FISH were prognostic for 2-year OS, including germinal centre versus nongerminal centre phenotype, MIB1, P53 expression, and $B C L 6$ and $B C L 2$ rearrangements (appendix pp 1-4).

In a planned subgroup analysis, no factor was predictive for a survival benefit of R-CHOP-14 versus R-CHOP-21 (figures 3, 4) including age, sex, stage, presence of B symptoms, bulky disease, WHO performance status, raised lactate dehydrogenase concentrations, or features of aggressive disease such as high proliferation rate and high IPI, although the probability of survival was non-significantly in favour of R-CHOP-21 in the subgroup with MIB1 of at least $90 \%$ (HR 2.09, $95 \%$ CI $0 \cdot 87-5 \cdot 00, p=0 \cdot 06)$. None of the gene abnormalities detected by use of FISH, including MYC rearrangement and the double-hit mutation status, or 


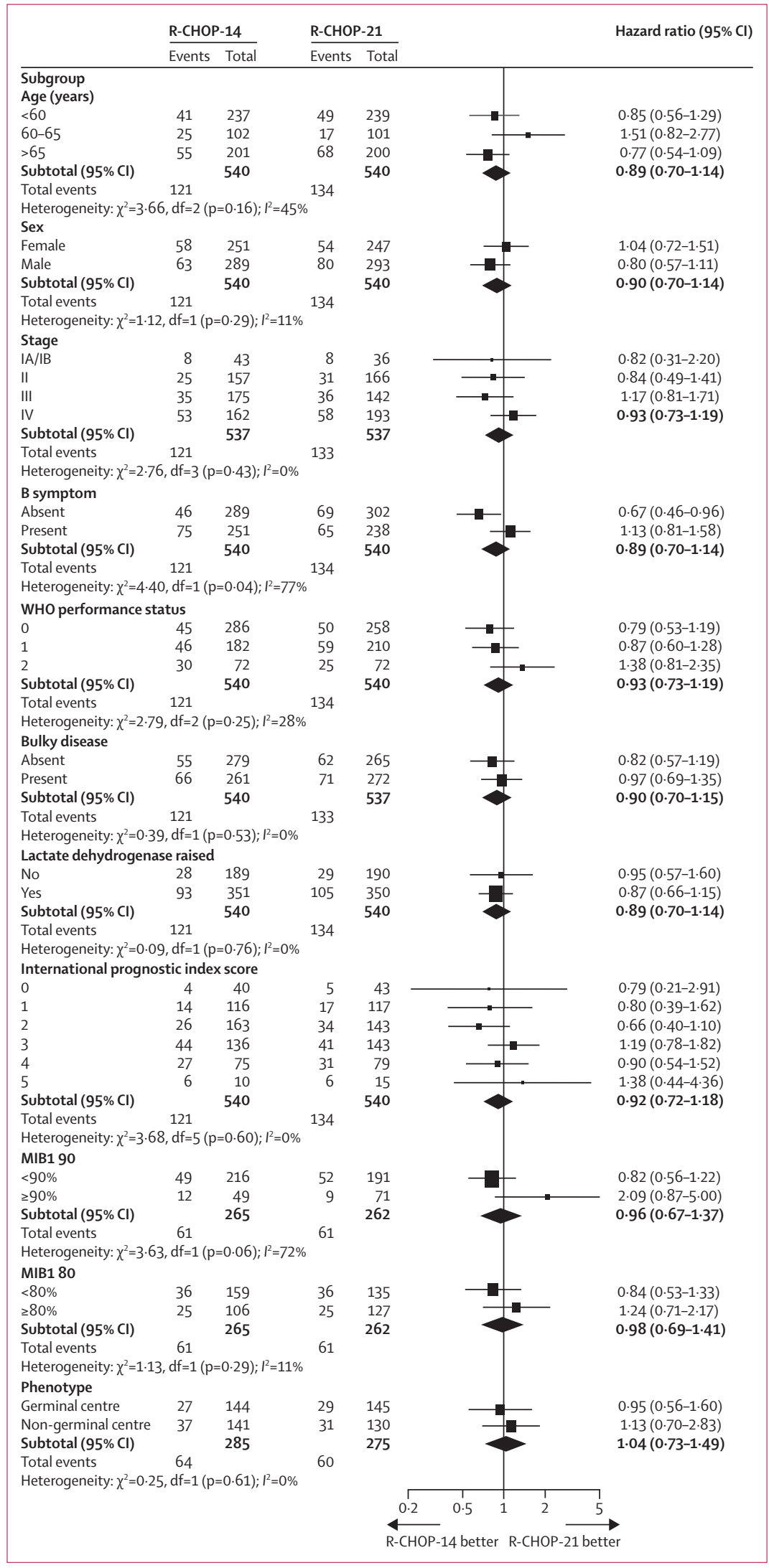

phenotype (germinal centre or non-germinal centre) were predictive for benefit in R-CHOP-14 or R-CHOP-21.

255 people died, 134 in the R-CHOP-21 group (85 lymphoma-related, three treatment-related, nine secondary malignancies, eight cardiac causes, 25 other illnesses, and four unknown causes) and 121 in the R-CHOP-14 group (79 lymphoma-related, nine treatment-related, six secondary malignancies, six cardiac causes, 17 other illnesses, and four unknown causes; appendix p 5). All cardiac deaths occurred at least 3 months after completion of treatment.

Frequencies of grade 3 or 4 neutropenia and febrile neutropenia were significantly higher with R-CHOP-21, probably due to the reduced use of G-CSF, whereas grade 3 or 4 thrombocytopenia was significantly higher in the R-CHOP-14 group (table 4). Of 422 patients in the R-CHOP-21 group who received eight cycles of treatment, $303(72 \%)$ had a toxicity of grade 3 or greater from cycles one to eight, and 282 (67\%) from cycles one to six, and $21(5 \%)$ from cycles seven to eight. 13 grade 5 toxicities were reported-neutropenic sepsis (one in R-CHOP-21 group and one in R-CHOP-14 group), non-neutropenic sepsis (one and two, respectively), suicide (two in R-CHOP-21 group), renal failure (one in R-CHOP-14 group), multiorgan failure (one in R-CHOP-14 group), and not specified (four in R-CHOP-14 group).

\section{Discussion}

The primary endpoint of superior overall survival with R-CHOP-14 compared with R-CHOP-21 was not met, and R-CHOP-14 did not improve response rates, PFS, or safety despite preservation of dose intensity. The two regimens were similar in all efficacy endpoints; however, the study was not powered to detect non-inferiority.

Similar results were presented at the 2012 American Society of Clinical Oncology conference by the GELA group from their study of 602 patients aged $60-80$ years. ${ }^{18}$ Patients were randomly assigned to eight cycles of either R-CHOP-14 or R-CHOP-21; however, G-CSF was administered at the investigator's discretion in both groups, resulting in a reduced dose intensity of doxorubicin and cyclophosphamide in the R-CHOP-14 group compared with the dose intensity in our study, and that of the original German reports., ${ }^{4,6}$ The smaller GELA study was powered for superiority and the results showed no difference in event-free survival, PFS, OS, response rate, or safety, supporting our findings. ${ }^{18}$ Of note, in routine clinical practice many patients now receive only six cycles of R-CHOP.

In our study, toxicities in the two groups were similar; R-CHOP-14 was associated with significantly more 
thrombocytopenia than was R-CHOP-21, but less neutropenia because of G-CSF primary prophylaxis. Treatmentrelated deaths were numerically higher in the R-CHOP-14 group (nine vs three); however, the difference was not significant $(\mathrm{p}=0 \cdot 082)$.

Few studies have shown a benefit of dose intensification with incorporation of rituximab versus standard rituximab-chemotherapy combinations, despite the targeting of high-risk populations. ${ }^{19-22}$ In a younger population, improved efficacy with the addition of etoposide to CHOP-14 was lost when combined with rituximab. ${ }^{13}$ First-line high-dose chemotherapy plus rituximab followed by autologous stem-cell transplant has also not improved outcomes compared with rituximab-chemotherapy alone..$^{23,24}$ By contrast, in a study by the GELA group, ${ }^{25}$ a significant survival advantage was reported with R-ACVBP compared with R-CHOP-21 in 380 young patients with low-risk or low-intermediate-risk disease. After a median follow-up of 44 months, the 3-year eventfree survival was $81 \%$ in the R-ACVBP group compared with $67 \%$ with R-CHOP-21, and 3-year PFS was $87 \%$ and $73 \%$, respectively. However, this improvement was associated with a three times increase in serious adverse events in the experimental group and febrile neutropenia in 38\% of patients, despite G-CSF prophylaxis, versus $7 \%$ with R-CHOP-21. In the Comment accompanying this GELA trial, the recommendation was that R-ACVBP should not be offered routinely until high-risk groups can be accurately identified to justify the additional toxicity. ${ }^{26}$ Of note, the 2 -year PFS was $80 \%$ in patients in our study who were younger than 60 years with IPI 0-2 receiving R-CHOP-21.

Molecular features such as high proliferation index, P53 deletion, and BCL2, MYC, and BCL6 rearrangements have previously been identified as poor prognostic markers in retrospective or small series..$^{16,27-29}$ In this study, only MYC rearrangement ( $10 \%$ of patients) was a poor prognostic marker in the univariate analysis but was not predictive for benefit of R-CHOP-14. Double-hit diffuse large B-cell lymphomas are known to have a worse prognosis, ${ }^{16,30-32}$ and although, in our study, this group of patients had poorer survival, in the multivariate analysis the difference was not significant and the effect of doublehit rearrangements might have been overestimated in previous retrospective studies. Molecular analysis showed no other poor prognostic subgroup or a cohort that benefited from R-CHOP-14. This finding was also reflected in the absence of significantly improved outcomes from R-CHOP-14 in patients with high IPI. With respect to the cell of origin, germinal centre diffuse large B-cell lymphoma has also been reported to have a better

Figure 4: Analysis of prognostic factors for progression-free survival Data are number, unless otherwise indicated. R-CHOP-14=cycles of rituximab plus cyclophosphamide, doxorubicin, vincristine, and prednisolone every 14 days. R-CHOP-21=cycles of rituximab plus cyclophosphamide, doxorubicin vincristine, and prednisolone every 21 days. $\mathrm{df}=$ degrees of freedom.

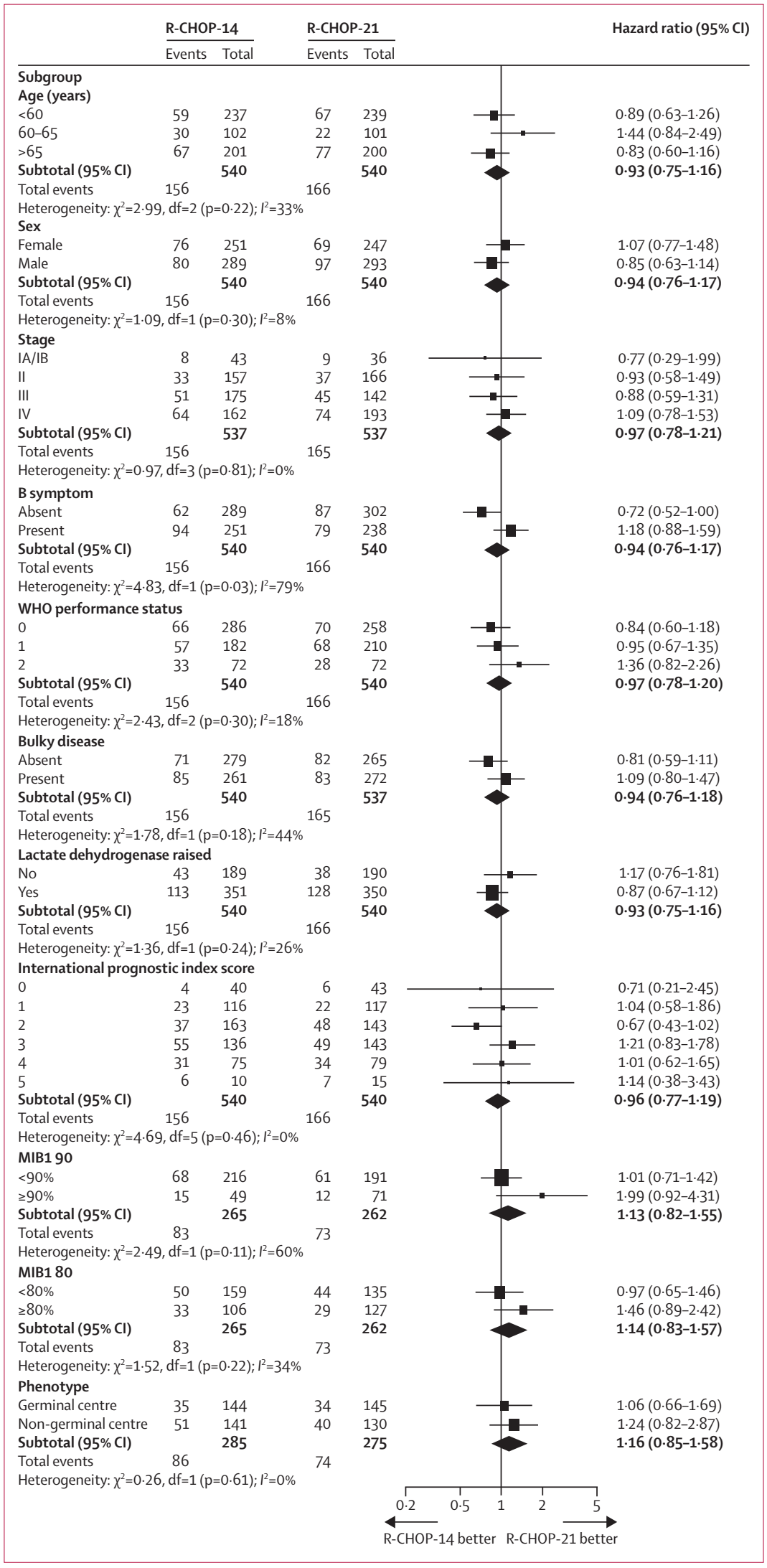




\begin{tabular}{|c|c|c|c|}
\hline & $\begin{array}{l}\text { R-CHOP-21 } \\
(n=534)\end{array}$ & $\begin{array}{l}\text { R-CHOP-14 } \\
(n=534)\end{array}$ & p value* \\
\hline All toxicity & $380(71 \%)$ & $290(54 \%)$ & .. \\
\hline Neutropenia & $318(60 \%)$ & $167(31 \%)$ & $<0.0001$ \\
\hline Febrile neutropenia & $58(11 \%)$ & $28(5 \%)$ & 0.0007 \\
\hline Thrombocytopenia & $28(5 \%)$ & $50(9 \%)$ & 0.010 \\
\hline Infection & $125(23 \%)$ & $96(18 \%)$ &.. \\
\hline Mucositis & $10(2 \%)$ & $14(3 \%)$ &.$\cdot$ \\
\hline Cardiac toxicity & $2(<1 \%)$ & $11(2 \%)$ & .. \\
\hline Nausea & $20(4 \%)$ & $22(4 \%)$ & .. \\
\hline Vomiting & $17(3 \%)$ & $19(4 \%)$ &.. \\
\hline Neurological toxicity & $38(7 \%)$ & $53(10 \%)$ &.. \\
\hline \multicolumn{4}{|c|}{$\begin{array}{l}\text { Data are number (\%), unless otherwise indicated. R-CHOP-21=cycles of rituximab } \\
\text { plus cyclophosphamide, doxorubicin, vincristine, and prednisolone every } 21 \text { days. } \\
\text { R-CHOP-14=cycles of rituximab plus cyclophosphamide, doxorubicin, vincristine, } \\
\text { and prednisolone every } 14 \text { days. *Only p values judged to be significant in multiple } \\
\text { testing are provided. }\end{array}$} \\
\hline
\end{tabular}

Panel: Research in context

\section{Systematic review}

We searched PubMed and Medline from January, 1993, until June, 2012, for publications in English, and American Society of Hematology and American Society of Clinical Oncology conference abstracts from January, 2008, until June, 2012, for reported randomised clinical trials with the terms "diffuse large B cell lymphoma", "CHOP chemotherapy", and "rituximab".

The benefit of combination rituximab and CHOP-14 $4^{12,13}$ (cycles of rituximab plus cyclophosphamide, doxorubicin, vincristine, and prednisolone every 14 days) or CHOP-21 (cycles of rituximab plus cyclophosphamide, doxorubicin, vincristine, and prednisolone every 21 days) was reported in four randomised studies, ${ }^{9,11}$ and CHOP-14 was compared with CHOP-21 in two phase 3 trials. ${ }^{4.6}$ The comparison of R-CHOP-14 and R-CHOP-21 in a study of elderly people showed no benefit of dose intensification; however, many patients received dose reductions in the R-CHOP-14 group. ${ }^{18} \mathrm{R}-\mathrm{CHOP}-14$ and R-CHOP-21 have not been compared in a large cohort study with inclusion of all patient and disease subgroups, and maintenance of dose intensity in both chemotherapy regimens.

\section{Interpretation}

Reports of studies have consistently shown the benefit of adding the anti-CD20 monoclonal antibody rituximab to CHOP in previously untreated diffuse large B-cell lymphoma, irrespective of the population assessed. Before the introduction of rituximab into the routine care of patients with diffuse large B-cell lymphoma, the findings of several reports showed a benefit of dose-intensified regimens compared with standard CHOP, including CHOP-14, rather than CHOP-21. The results of our randomised, phase 3 study of the comparison of R-CHOP-14 with R-CHOP-21 in 1080 patients from all prognostic groups showed that R-CHOP-14 is not superior to R-CHOP-21; therefore, in the era of rituximab, $\mathrm{R}$-CHOP-21 remains the standard first-line treatment for diffuse large B-cell lymphoma.

prognosis than does the non-germinal centre type; ; $^{27,33-35}$ although a difference was not noted in our study, the Hans criteria method for determination of the cell of origin is inferior to gene expression profiling. Nevertheless, while the tissue used was of suitable quality for definition of the immunophenotype in only $50 \%$ of cases, this analysis is one of the largest undertaken within a prospective trial.
R-CHOP-14 has efficacy in patients with diffuse large B-cell lymphoma (panel). However, it is not superior to standard R-CHOP-21 and this trial was not powered to show non-inferiority of R-CHOP-14 to R-CHOP-21; therefore, R-CHOP-21 remains the standard reference regimen. Results of the biomarker analysis and clinical stratification did not identify a subgroup of patients who would benefit from a more intensified regimen.

\section{Contributors}

DC designed the study, had study oversight, and contributed to data interpretation, writing, and approval of the report. EAH did the data gathering, analysis, and interpretation, literature searches, and wrote the report. AJ designed the study, and did the central histological review and molecular analysis. WQ designed the study, analysed and interpreted data, produced figures, and wrote the report. PS, PM, and JG gathered, interpreted, and analysed the data. CP, KMA, JAR, AM, JD, DT, AK, PJ, and DL gathered and interpreted the data. DC and EAH contributed equally. All authors have reviewed and approved the final version of the report.

\section{Trial investigators}

R Aitchison (Stoke Mandeville, and Wycombe Hospitals); D M Alderson (Trafford General Hospital); M A W Aldouri (Medway Maritime Hospital); S Al-Ismail (Singleton Hospital); F Al-Refaie (Princess Alexandra Hospital); K Ardeshna (Mount Vernon Cancer Centre and University College London); S Basu (New Cross Hospital); J Beard (Conquest and Eastbourne District General Hospitals); K Benstead (Cheltenham General and Gloucester Royal Hospitals); P Bevan (St Richards Hospital); N Bienz (Wexham Park Hospital); A Biswas (Royal Preston Hospital); N Blesing (Great Western Hospital); L Bond (York District Hospital); A Borg (Warwick Hospital); A Brownell (King George Hospital and Queens Hospital Romford); P Cervi (Basildon Hospital); D Chan-Lam (Barnsley District General Hospital); F Clark (Queen Elizabeth Hospital, Birmingham); P Coates (Queen Elizabeth Hospital, Kings Lynn); D Culligan (Aberdeen Royal Infirmary); J Cullis (Salisbury District Hospital); P Cumber (Prince Philip Hospital); D Cunningham (Royal Marsden NHS Foundation Trust); A Cuthbert (Airedale General Hospital); R Dang (James Cook University Hospital); N Davidson (Broomfield Hospital); J Davies (Western General Hospital); M Dyer (Leicester Royal Infirmary); R Ezekwesili (Darent Valley Hospital); S Fernandes (Russells Hall Hospital); P Fields (Guy's and St Thomas' Hospital); P Forsyth (Raigmore Hospital); E Gallop-Evans (Velindre Hospital); D Gillett (Kent and Sussex Hospital and Kent Oncology Centre); D Gowans (Sunderland Royal Hospital); H Grech (Royal Berkshire Hospital); C Hall (Harrogate District Hospital); B Hancock (Royal Hallamshire and Weston Park Hospitals); J Harrison (Hemel Hempstead General and Watford General Hospitals);

B Harrison (Walsgrave Hospital); C Hoyle (Glan Clwyd District General Hospital); R Johnson (Leeds General Infirmary and St James' University Hospital); P Johnson (Cancer Research UK Centre, Southampton); S Jones (Kings Mill Hospital); J Joseph (Doncaster Royal Infirmary); M Joyner, (Royal Devon and Exeter Hospital); S Killick (Royal Bournemouth Hospital); C Knechtli (Royal United Hospital); A Kruger (Royal Cornwall Hospital); A Lakhani (Princess Royal University Hospital); A Lennard (Royal Victoria Infirmary); A Lister (St Bartholomews Hospital); M Lumley (Good Hope Hospital, Sutton Coldfield); M Lyttelton (Kettering Hospital); M Macheta (Blackpool Victoria Hospital); S Mackinnon (Royal Free Hospital); R Marcus (Addenbrookes Hospital); Z Maung (University Hospital of North Tees); P Mckay (Western Infirmary); A McMillan (Nottingham City Hospital); D Meiklejohn (Ninewells Hospital); J Mercierca (Epsom and St Helier Hospitals); D Milligan (Birmingham Heartlands Hospital); A Milne (North Hampshire Hospital); M Moody (West Suffolk Hospital); P Murray (Essex County Hospital); L Newton (Bradford Royal Infirmary); D O'Brien (Southport and Formby District General Hospital); A O'Callaghan (St Marys Hospital, Portsmouth); A Okhandiar (Borders General Hospital); A Pagluica (Kings College Hospital); N Panoskaltsis (Northwick Park Hospital); R Patmore (Hull Royal Infirmary); R Pettengell (St Georges Hospital); A Pettitt (Royal Liverpool University 
Hospital); C Pocock (Kent and Canterbury Hospital, Willam Harvey and Queen Elizabeth Queen Mother Hospitals); C Pollard (Mayday University Hospital); C Price (Bristol Haematology and Oncology Centre); J Radford (University of Manchester and the Christie NHS Foundation Trust); P Revell (Staffordshire General Hospital); C Rist (Worthing Hospital); J Ross (Northampton General Hospital);

C Rowntree (University Hospital of Wales); S Rule (Derriford Hospital); K Ryan (Manchester Royal Infirmary); S Sadullah (James Paget Hospital); G Satchi (Whiston Hospital); J Seale (Ysbyty Gwynedd); M Sekhar (West Middlesex University Hospital); I Singer (Monklands and Wishaw General Hospitals); A Smith (Derbyshire Royal Infirmary); S Stern (East Surrey Hospital); R Stockley (Worcester Royal Hospital); G Summerfield (Queen Elizabeth Hospital, Gateshead); D Turner (Torbay Hospital); A Virchis (Barnet and Chase Farm Hospitals); A Webb (Royal Sussex County Hospital); P Williamson (Darlington Memorial Hospital); S Willoughby (Hereford County Hospital); J Wimperis (Norfolk and Norwich University Hospital); B Woodcock (University Hospital Aintree); D Wright (Dewsbury District, Pinderfields General and Pontefract General Hospitals).

\section{Conflicts of interest}

DC received research grants from Roche, Amgen, Sanofi-Aventis, Novartis, Astra-Zeneca, Merck KGA, and Celgene; participated on compensated advisory boards for Amgen, Roche, Merck, and Sanofi-Aventis, and uncompensated advisory boards for Roche (honoraria), Merck, and Sanofi-Aventis; and provided uncompensated expert testimony for Amgen. EAH has received travel expenses from Roche. AJ has received research grants from Roche and Genentech. CP has participated on compensated advisory boards for Roche and Pfizer, and received travel expenses from Roche. KMA has received research funding and honoraria from Roche. JAR has received research grants from Millennium, and provided expert testimony for Millennium Pharmaceuticals, Bayer-Schering, Roche, Napp Pharmaceuticals, Novartis, and GlaxoSmithKline. AM has received a research grant from Roche, and consultancy fees, honoraria, and travel expenses from Roche. JD has received consultancy fees and travel expenses from Roche. DT has received travel expenses from Roche. PJ has participated on a compensated advisory board for and received travel expenses from Roche. DL has received research grants from Roche and Chugai Pharma; participated on compensated advisory boards for Roche, Chugai, Amgen, and Hospira; and received honoraria from Roche, Chugai, and Celgene. The other authors declare that they have no conflicts of interest.

\section{Acknowledgments}

Cancer Research UK provided endorsement and funding, and National Health Service provided funding to the National Institute for Health Research Biomedical Research Centres at both University College London and the Royal Marsden NHS Foundation Trust and Institute of Cancer Research (all London, UK). Chugai Pharmaceuticals provided an educational grant and lenograstim.

\section{References}

1 Armitage JO, Weisenburger DD. New approach to classifying non-Hodgkin's lymphomas: clinical features of the major histologic subtypes. Non-Hodgkin's lymphoma classification project. J Clin Oncol 1998; 16: 2780-95.

2 Fisher RI, Gaynor ER, Dahlberg S, et al. Comparison of a standard regimen (CHOP) with three intensive chemotherapy regimens for advanced non-Hodgkin's lymphoma. N Engl J Med 1993; 328: 1002-06.

3 Linch DC, Yung L, Smith P, et al. Final analysis of the UKLG LY02 trial comparing 6-8 cycles of CHOP with 3 cycles of CHOP followed by a BEAM autograft in patients $<65$ years with poor prognosis histologically aggressive NHL. Br J Haematol 2010; 149: 237-43.

4 Pfreundschuh M, Trumper L, Kloess M, et al. Two-weekly or 3-weekly CHOP chemotherapy with or without etoposide for the treatment of elderly patients with aggressive lymphomas: results of the NHL-B2 trial of the DSHNHL. Blood 2004; 104: 634-41.

5 Ohmachi K, Tobinai K, Kobayashi Y, et al. Phase III trial of CHOP-21 versus CHOP-14 for aggressive non-Hodgkin's lymphoma: final results of the Japan Clinical Oncology Group Study, JCOG 9809. Ann Oncol 2011; 22: 1382-91.
6 Pfreundschuh M, Trumper L, Kloess M, et al. Two-weekly or 3-weekly CHOP chemotherapy with or without etoposide for the treatment of young patients with good-prognosis (normal LDH) aggressive lymphomas: results of the NHL-B1 trial of the DSHNHL. Blood 2004; 104: 626-33.

7 Reyes F, Lepage E, Ganem G, et al. ACVBP versus CHOP plus radiotherapy for localized aggressive lymphoma. N Engl J Med 2005; 352: 1197-205.

8 Tilly H, Lepage E, Coiffier B, et al. Intensive conventional chemotherapy (ACVBP regimen) compared with standard CHOP for poor-prognosis aggressive non-Hodgkin lymphoma. Blood 2003 . 102: 4284-89.

9 Coiffier B, Lepage E, Briere J, et al. CHOP chemotherapy plus rituximab compared with CHOP alone in elderly patients with diffuse large-B-cell lymphoma. N Engl J Med 2002; 346: 235-42.

10 Coiffier B, Thieblemont C, Van Den Neste E, et al. Long-term outcome of patients in the LNH-98.5 trial, the first randomized study comparing rituximab-CHOP to standard CHOP chemotherapy in DLBCL patients: a study by the Groupe d'Etudes des Lymphomes de l'Adulte. Blood 2010; 116: 2040-45.

11 Habermann TM, Weller EA, Morrison VA, et al. Rituximab-CHOP versus CHOP alone or with maintenance rituximab in older patients with diffuse large B-cell lymphoma. J Clin Oncol 2006; 24: 3121-27.

12 Pfreundschuh M, Schubert J, Ziepert M, et al, for the German High-Grade Non-Hodgkin Lymphoma Study Group (DSHNHL). Six versus eight cycles of bi-weekly CHOP-14 with or without rituximab in elderly patients with aggressive CD20+ B-cell lymphomas: a randomised controlled trial (RICOVER-60). Lancet Oncol 2008; 9: 105-16.

13 Pfreundschuh M, Trumper L, Osterborg A, et al, for the MabThera International Trial (MInT) Group. CHOP-like chemotherapy plus rituximab versus CHOP-like chemotherapy alone in young patients with good-prognosis diffuse large-B-cell lymphoma: a randomised controlled trial by the MabThera International Trial (MInT) Group. Lancet Oncol 2006; 7: 379-91.

14 Jaffe ES, Harris NL, Stein H, Vardiman JW. World Health Organisation Classification of Tumours. Pathology and genetics of tumours of haematopoietic and lymphoid tissues. Lyon: IARC Press, 2001.

15 Hans CP, Weisenburger DD, Greiner TC, et al. Confirmation of the molecular classification of diffuse large B-cell lymphoma by immunohistochemistry using a tissue microarray. Blood 2004; 103: 275-82.

16 Barrans S, Crouch S, Smith A, et al. Rearrangement of MYC is associated with poor prognosis in patients with diffuse large B-cell lymphoma treated in the era of rituximab. J Clin Oncol 2010; 28: 3360-65.

17 Cheson BD, Horning SJ, Coiffier B, et al. Report of an international workshop to standardize response criteria for non-Hodgkin's lymphomas. NCI Sponsored International Working Group. J Clin Oncol 1999; 17: 1244.

18 Delarue R, Tilly H, Salles GA, et al. R-CHOP14 compared to R-CHOP21 in elderly patients with diffuse large B-cell lymphoma (DLBCL): final analysis of the LNH03-6B GELA study. J Clin Oncol 2012; 30: 8021 (abstr).

19 Stiff PJ, Unger JM, Cook J, et al. Randomized phase III U.S./Canadian intergroup trial (SWOG S9704) comparing $\mathrm{CHOP} \pm \mathrm{R}$ for eight cycles to $\mathrm{CHOP} \pm \mathrm{R}$ for six cycles followed by autotransplant for patients with high-intermediate (H-Int) or high IPI grade diffuse aggressive non-Hodgkin lymphoma (NHL). J Clin Oncol 2011; 29: 8001 (abstr).

20 Tarella C, Zanni M, Di Nicola M, et al. Prolonged survival in poor-risk diffuse large B-cell lymphoma following front-line treatment with rituximab-supplemented, early-intensified chemotherapy with multiple autologous hematopoietic stem cell support: a multicenter study by GITIL (Gruppo Italiano Terapie Innovative nei Linfomi). Leukemia 2007; 21: 1802-11.

21 Vitolo U, Chiappella A, Angelucci E, et al. Dose-dense and high-dose chemotherapy plus rituximab with autologous stem cell transplantation for primary treatment of diffuse large B-cell lymphoma with a poor prognosis: a phase II multicenter study. Haematologica 2009; 94: 1250-58.

22 Glass B, Ziepert M, Reiser M, et al. High-dose therapy followed by autologous stem-cell transplantation with and without rituximab for primary treatment of high-risk diffuse large B-cell lymphoma. Ann Oncol 2010; 21: 2255-61. 
23 Le Gouill S, Milpied NJ, Lamy T, et al. First-line rituximab (R) high-dose therapy (R-HDT) versus R-CHOP14 for young adults with diffuse large B-cell lymphoma: Preliminary results of the GOELAMS 075 prospective multicenter randomized trial. J Clin Oncol 2011; 29: 8003 (abstr).

24 Schmitz N, Nickelsen M, Ziepert M, et al. Conventional chemoimmunotherapy (R-CHOEP-14) or high-dose therapy (R-Mega-CHOEP) for young, high-risk patients with aggressive B-cell lymphoma: Final results of the randomized Mega-CHOEP trial of the German High-Grade Non-Hodgkin Lymphona Study Group (DSHNHL). J Clin Oncol 2011; 29: 8002 (abstr).

25 Recher C, Coiffier B, Haioun C, et al. Intensified chemotherapy with ACVBP plus rituximab versus standard CHOP plus rituximab for the treatment of diffuse large B-cell lymphoma (LNH03-2B): an open-label randomised phase 3 trial. Lancet 2011; 378: 1858-67.

26 Vose JM. Intensified chemotherapy for diffuse large B-cell lymphomas. Lancet 2011; 378: 1828-29.

27 Wilson WH, Dunleavy K, Pittaluga S, et al. Phase II study of dose-adjusted EPOCH and rituximab in untreated diffuse large B-cell lymphoma with analysis of germinal center and post-germinal center biomarkers. J Clin Oncol 2008; 26: 2717-24.

28 Salles G, de Jong D, Xie W, et al. Prognostic significance of immunohistochemical biomarkers in diffuse large B-cell lymphoma: a study from the Lunenburg Lymphoma Biomarker Consortium. Blood 2011; 117: 7070-78.

29 Savage KJ, Johnson NA, Ben-Neriah S, et al. MYC gene rearrangements are associated with a poor prognosis in diffuse large B-cell lymphoma patients treated with R-CHOP chemotherapy. Blood 2009; 114: 3533-37.
30 Johnson NA, Savage KJ, Ludkovski O, et al. Lymphomas with concurrent $B C L 2$ and $M Y C$ translocations: the critical factors associated with survival. Blood 2009; 114: 2273-79.

31 Li S, Lin P, Fayad LE, et al. B-cell lymphomas with MYC/8q24 rearrangements and IGH@BCL2/t(14;18)(q32; 21$)$ : an aggressive disease with heterogeneous histology, germinal center B-cell immunophenotype and poor outcome. Mod Pathol 2012; 25: $145-56$.

32 Green TM, Young KH, Visco C, et al. Immunohistochemical double-hit score is a strong predictor of outcome in patients with diffuse large B-cell lymphoma treated with rituximab plus cyclophosphamide, doxorubicin, vincristine, and prednisone. J Clin Oncol 2012; 30: 3460-67.

33 Thieblemont C, Briere J, Mounier N, et al. The germinal center/activated B-cell subclassification has a prognostic impact for response to salvage therapy in relapsed/refractory diffuse large B-cell lymphoma: a bio-CORAL study. J Clin Oncol 2011; 29: 4079-87.

34 Lenz G, Wright G, Dave SS, et al. Stromal gene signatures in large-B-cell lymphomas. N Engl J Med 2008; 359: 2313-23.

35 Alizadeh AA, Eisen MB, Davis RE, et al. Distinct types of diffuse large B-cell lymphoma identified by gene expression profiling. Nature 2000; 403: 503-11. 